
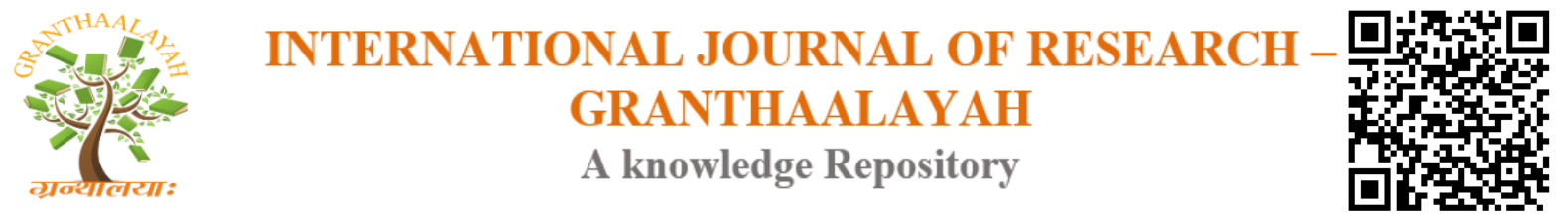

Science

\title{
LANGUAGE OF A BUILDING
}

\author{
Anjali Jain *1, Ar. Soma A Mishra ${ }^{2}$, Sejal Selwadiya ${ }^{3}$ \\ $* 1,2,3$ B. Arch, SDPS Women's College, India
}

\begin{abstract}
The research aims at understanding the language of a building, the overall expression it creates by its basic elements like line, plane and form. On altering these elements the principles of designing like form, symmetry, balance, proportion etc gets altered resulting in the change in the expression of a building. The study comprises of the characteristics and emotional effect created by different basic geometrical forms and how these forms change the aesthetics of the building. It also aims at understanding the language through self-analysis of few buildings. Architecture is supposed to be something 'creative', and creativity is not subjected to analysis but creativity is itself founded on the knowledge of obvious and typical. Therefore, to create creative there should be the knowledge of typical.
\end{abstract}

Keywords: Language of a Building; Characteristics; Emotional Effect; Elements; Principles.

Cite This Article: Anjali Jain, Ar. Soma A Mishra, and Sejal Selwadiya. (2018). "LANGUAGE OF A BUILDING." International Journal of Research - Granthaalayah, 6(10), 139-145. https://doi.org/10.29121/granthaalayah.v6.i10.2018.1171.

\section{Introduction}

Language is a method through which communication is done. Similarly, 'language of a building' is a communication method of a building. It is the expression of a building and an impression it creates on the viewer through its spaces.

Just like we communicate through sentences, building expresses itself through its spaces and just like the sentences are made through words, the spaces are made through the basic and the most important elements like point, line, plane, form and through these elements arise masses,spaces,proportion,symmetery,balance,contrast,pattern,decoration and massing. The above given elements and principles govern the language of a building.

The language of building is related to human and how he responds to the spaces. Something pleases a viewer, others do not. Why does this happen? This is the question which allows us to know further how different spaces are composed from the basic elements and how it changes the emotional state of a viewer. 
Theoretically there are as many aesthetic viewpoints as there are individuals. Seen subjectively, each viewpoint is equally valid and it is quite impossible to objectively state whether one point of view is Better. But the evaluation of two individuals may differ in degree but it is not likely to differ in kind.

Today, architecture has a very comprehensive meaning in its entirety it concerns about every kind of building task, be it a school, a hospital, a hotel or a toilet. If we now look for a common factor in this diverse list of buildings and areas, we shall find it in the concept of space. So "architecture is the conscious creation of utilitarian spaces constructed from materials in such a way that the whole is both technically and aesthetically satisfying." (Prammer, 1973)

\section{Materials and Methods}

Further are given the characteristics of different geometrical forms and the emotional effect they create on a viewer. All of these outcomes are based on the study.

\section{The Sphere}

\section{Characteristics}

- Regular continuous surface unbroken by lines, edges or corners.

- Has no directional quality.

- No horizontal or vertical emphasis.

- Static neutrality.

- Closed within it-self.

- Visual quality of repulsion from outside. (its convex from outside which is uninviting.)

- No interesting points for eye to focus and therefore its fruitless flitting will be replaced by awareness of total form.

\section{Emotional Effect}

\section{From Outside}

1) The emotional effect produced on the observer will be one of lack of concentration, of diffuseness and ultimately of restlessness.

2) The observer is to deprive him of a sense of orientation.

\section{From inside}

The sphere is concave therefore attracting, but from all sides, resulting in equilibrium of forces leading towards centre. This imaginary centre will arouse feeling of concentration, of repose and of orientation to itself.(Prammer, 1973) (Ching)

\section{The Hemisphere}

- The dome externally retains the diffuse quality of the sphere but its continuity is sharply terminated at the rim.

- $\operatorname{Rim}$ is of great visual emphasis as the eye repulsed by dome will rest on the rim.

\section{Emotional effect:}

From Outside

1) Observer will feel an impulsion to move around hemisphere, leading to circular movement. 


\section{From Inside}

The centre of the dome and flat circle will coincide making it a mental and visual focal point.

\section{The Cube}

The cube is described as a mass externally composed of plane surfaces, lines and corners. There are two kinds of plane surfaces present in cube: horizontal and vertical. The observer at the ground has major impression of vertical plane surface.

- The vertical blank square neither invites nor repulses, it stands both physically and visually impenetrable.

- The four vertical sides of cube faces four directions and all directions are equally emphasized. Therefore the cube has no directional quality.

- Each vertical edge of cube has a visual force. When each vertical edge meets two horizontal edges, the corner that is formed becomes imbued with visual dominance.

\section{Emotional Effect}

From Outside

- Feeing of tension arises due to attraction from two corners in the frontal view of the cube.

- Tension with impenetrability of the form will cause an observer to remain stationary wherever he is.

\section{From Inside}

- the plane surfaces of cube has inability to focus on anything of significance, together with prison like enclosure, leads to visual monotony and emotional depression (Prammer, 1973) (Ching)

\section{The Pyramid}

- The sides of the pyramid are formed of triangles. The triangle is a shape that simultaneously attracts the eye towards its corners, and if one of these is more prominent than the others, then it is this corner that the eye will travel.

- The corner that is located vertically is the one that is the most dominant.

- The effect of concentration of visual forces at one point imbues that point with an exclusive power of attraction which is far greater than that of any corner of cube.

Further some principles also play a great role in changing the overall language of a building. These principles are stated below:

\section{Proportion}

- To be most satisfying mass must have one dominant dimension.

- Certain geometrical form appears uninteresting like sphere and cube because geometrically they are perfect but emotionally void.

- Other geometrical forms like rectanguloid, the pyramid, cylinder emphasis one dimension and hence more satisfying.

An error of scale in the dimensioning of a dwelling space can have disturbing psychological effects.

- A too low ceiling can create a feeling of depression.

- Too high, it may result in feeling of insecurity. 
- Too large a space can destroy the sense of shelter and intimacy.

- Thus scale and proportion go beyond mere aesthetic effects, they determine the inhabitability of space and mass.

\section{Symmetry}

The human being is able to appreciate symmetry because he himself is symmetrically constructed. Symmetry is not a quality that adheres only to the object itself, but has relevance to the vertical stance of the observer. As the observer moves, the imaginary vertical plane moves with him. As the object is continually seen from different angles, it may appear symmetrical from one side and not from another.

\section{Emotional Effect}

- A symmetrical object presents a view that is somehow visually more stable and better organized.

- It is easier to identify and retain in memory than asymmetrical one.

- Arouses a sense of visual stability.

- Excessive symmetry i.e. excessive orderliness can also appear monotonous.

Note: an architectural object must combine orderliness with interest. (Prammer, 1973) (Ching)

\section{Balance}

It is used to denote visual equilibrium whereby the equilibrium does not consist of equal elements distributed symmetrically about a centre of gravity, but unequal elements distributed asymmetrically and yet remaining balanced using emphatic forms in symmetry (so that they also have a little tension to create interest). For example imagine a rectangle divided into two equal parts painted with yellow and blue color respectively. Here yellow being the dominant color will only be emphasized. Now imagine another rectangle with blue painted on a larger portion and the yellow on lesser portion. This would be a balanced rectangle as the yellow portion would be seen through its strong color and the blue portion would be seen because of its larger area. Similar objects have differing visual weight age. Visual weightage is given below: -

- Vertical>horizontal >neutral

- Pyramidal $>$ vertical $>$ rectanguloid $>$ horizontal rectanguloid $>$ cube $>$ cylinder $>$ sphere

- Points $>$ lines $>$ surfaces $>$ openings

- Solid>perforated

- Projecting $>$ receding

- Convex>concave

- Bright $>$ dark

- As a corollary to the last named we may add: -

- Red>yellow>white> green $>$ blue $>$ black

For example

- A vertical mass which in itself has maximum weight age may appear weaker if it is extensively perforated, or if it is painted a dull color, or if it is covered with horizontal bands, in which case it may be easily balanced by interior mass. 
- A squat mass may be made to look more vertical if it is painted over with vertical strips and its weight age thus increased.

Symmetry evokes stability, balance evokes dynamism. (Prammer, 1973) (Ching)

\section{Case Study}

\section{Gandhi Smarak SANGRAHALAYA}

(Self-analysis by the researcher)

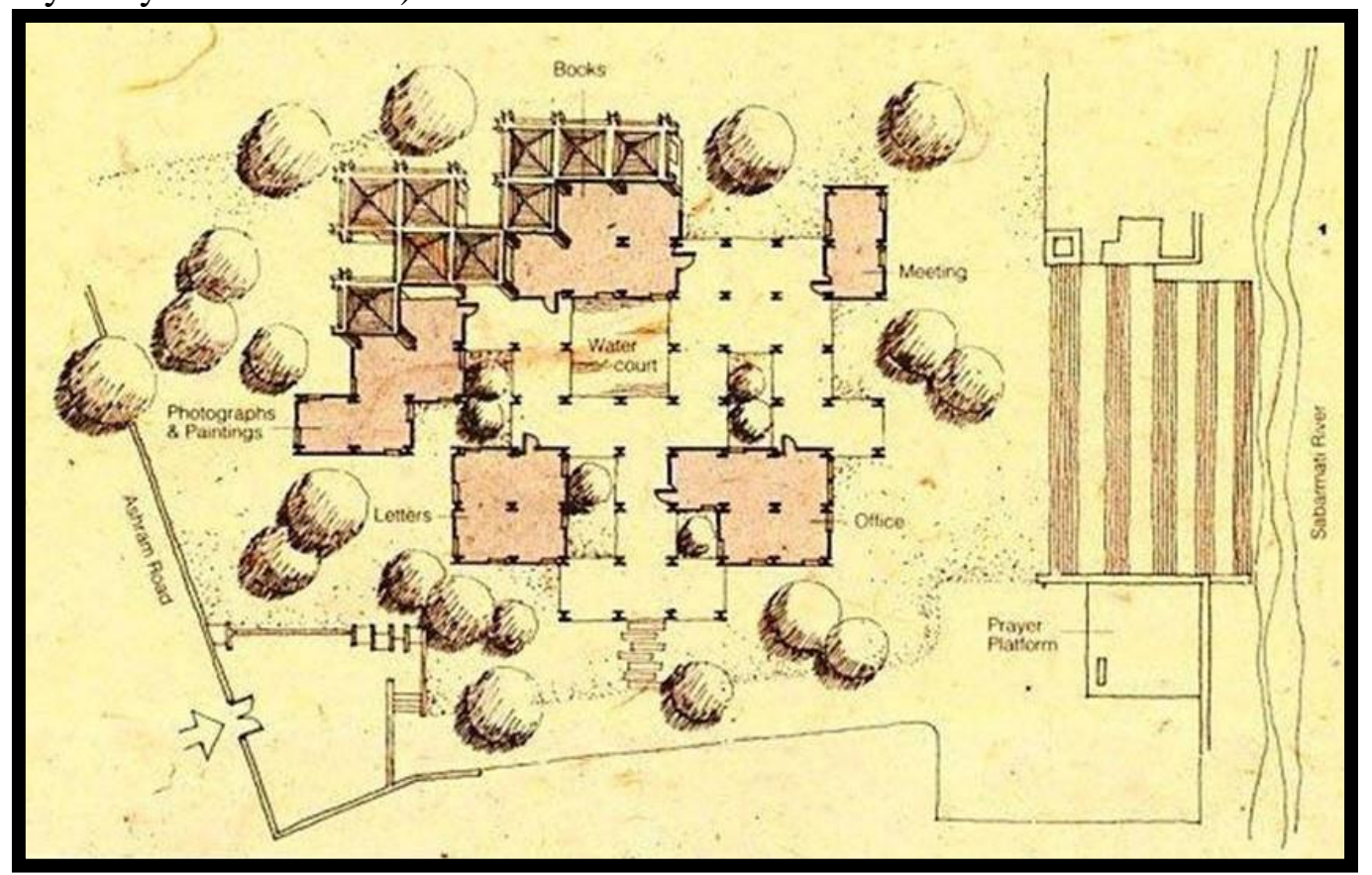

Figure 1: plan of Gandhi smarak sangrahalaya

Source: https://thearchiblog.wordpress.com/2011/01/09/charles-correa-gandhi-smaraksangrahalaya-and-jeevan-bharti/

"I do not want my house to be walled on all sides and my windows to be stuffed. I want the cultures of all the lands to be blown about my house as freely as possible. but I refuse to be blown off my feet by any of them" -MAHATMA GANDHI

Gandhi Smarak Sangrahalaya is the memorial museum built in homage to mahatma and to propagate his ideas, it houses letters, photographs and other documents which trace the freedom movement launched by Gandhi. It is designed by Indian master architect Charles Correa.

To design a museum for so simple yet so eminent figure in the history of India was itself a task and the museum we see now indubitably portrays the ideas and principles of lifestyle of Gandhi. It is a place providing a visitor a sense of peace and simplicity. Its overall form is not something complex and dynamic but represents neutrality. The basic form used is of a square because no dimension is dominated in a square resulting in a overall neutrality of a space just like the neutral lifestyle of Gandhi. The pathways are created within the squares leading oneself to the central water court. The pathways designed here break the concept of monotonous corridors with packing walls but are open with no walls and only roof. To give the essence of peace some squares are kept 
closed and some are kept semi open while the others represent the water court and courtyards which are open to sky. Such type of amalgamation of open and closed spaces adds to the experience of a visitor keeping the visitor connected to the blessings of sky and free- flowing breeze. The humane scale gives the homely feeing to viewer and comfort of the viewer comes into being. No such materials like glass or steel are used instead to add to the peace and simplicity natural materials like stone flooring, brick wall, wooden windows are used. The modules are arranged in an irregular manner to represent a traditional Indian village and the pattern created by tiled roof adds to the sense of village. Correa's habit of designing pathways can be seen here also, giving a viewer a quality experience of the aura of the spaces. Further like other museums with only displaying areas which bore the visitor, Correa gave sitting spaces at proper intervals near the open spaces to help to visitor relax for a moment before walking again.
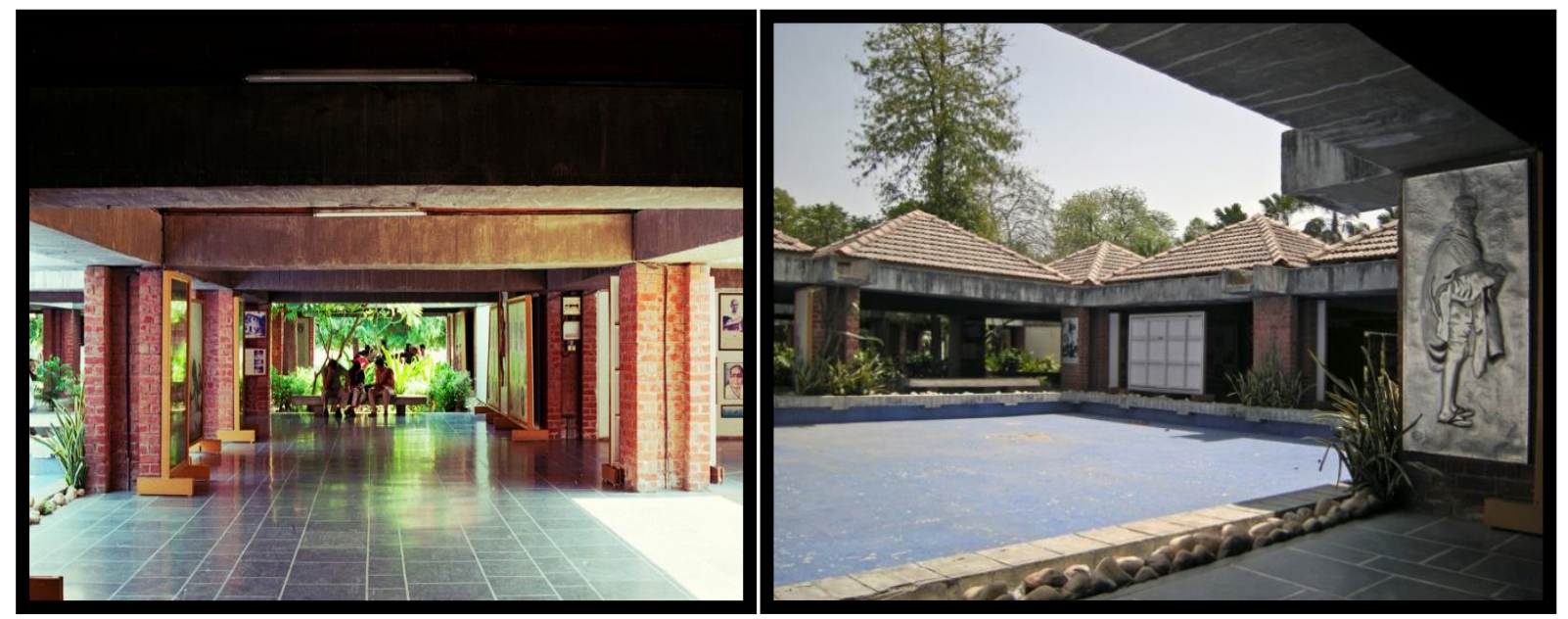

\section{Conclusions and Recommendations}

Different basic elements, used with different principles, create different impressions in a mind of a human being. Ultimately it is the human being who is going to reside in a building or visit it. Therefore appropriate elements should be used to design spaces for human beings according to his needs. One can reside in box also but mere residing is not worth. .In five senses of human, eye is the one which gives the most spontaneous affect to our brain. Whatever we perceive through our eyes creates an impression within us. Therefore there is need to have certain aesthetics that satisfy the living of a human being and pleases our eye. Understanding the elements allows us to design better spaces for different activities of a human being.

\section{Acknowledgements}

The successful completion of project is the result of sincere efforts, guidance and inspiration from many people. I would like to pay my heartiest gratitude to all those sources, person who have helped me directly or indirectly in achieving the stage of this project. I am highly indebted to all my teachers for their guidance. I am thankful to my dissertation head Er. Utkarsh Jain sir for his constant trust for our class and dissertation sub-head AR. Khushboo Lahori. I am thankful to Ar. Soma Anil Mishra ma'am for her constant supervision as well as for providing necessary information regarding my topic and also their support in completing it. I am thankful to my friends 
for motivation and discussions. Last but not least my family who has helped me in each and every step of life.

\section{References}

[1] Ching, F. D. Form Space and Order. CBS Publishers.

[2] Frampton, K. (1996). Charles Correa. The Peppin Press.

[3] Prammer, V. (1973). Design Fundamentals in Architecture. somaiya publication.

*Corresponding author.

E-mail address: anjali.jain1200@ gmail.com 